University of Nebraska - Lincoln

DigitalCommons@University of Nebraska - Lincoln

Agronomy \& Horticulture -- Faculty Publications

Agronomy and Horticulture Department

2001

\title{
Conversion of AFLP Bands into High-Throughput DNA Markers
}

\author{
K. Meksem \\ Southern Illinois University, meksemk@siu.edu \\ E. Ruben \\ Southern Illinois University, eruben@ou.edu \\ D. L. Hyten \\ Southern Illinois University, david.hyten@unl.edu \\ K. Triwitayakorn \\ Southern Illinois University, kanokporn.tri@mahidol.ac.th \\ D. A. Lightfoot \\ Southern Illinois University, ga4082@siu.edu
}

Follow this and additional works at: https://digitalcommons.unl.edu/agronomyfacpub

Part of the Agricultural Science Commons, Agriculture Commons, Agronomy and Crop Sciences

Commons, and the Plant Breeding and Genetics Commons

Meksem, K.; Ruben, E.; Hyten, D. L.; Triwitayakorn, K.; and Lightfoot, D. A., "Conversion of AFLP Bands into High-Throughput DNA Markers" (2001). Agronomy \& Horticulture -- Faculty Publications. 776.

https://digitalcommons.unl.edu/agronomyfacpub/776

This Article is brought to you for free and open access by the Agronomy and Horticulture Department at DigitalCommons@University of Nebraska - Lincoln. It has been accepted for inclusion in Agronomy \& Horticulture -Faculty Publications by an authorized administrator of DigitalCommons@University of Nebraska - Lincoln. 


\title{
Conversion of AFLP Bands into High-Throughput DNA Markers
}

\author{
K. Meksem, E. Ruben, D. Hyten, K. Triwitayakorn, and D. A. Lightfoot
}

Department of Plant Soil and General Agriculture (Room 176), Center for Excellence in Soybean Research, Teaching and Outreach, Southern Illinois University at Carbondale, Carbondale, IL 629014415, USA

Corresponding author-K. Meksem, email meksemk@siu.edu

\begin{abstract}
The conversion of AFLP bands into polymorphic sequence-tagged-site (STS) markers is necessary for high-throughput genotype scoring. Technical hurdles that must be overcome arise from genome complexity (particularly sequence duplication), from the low-molecular- weight nature of the AFLP bands and from the location of the polymorphism within the AFLP band. We generated six STS markers from ten AFLP bands (four AFLPs were from co-dominant pairs of bands) in soybean (Glycine max). The markers were all linked to one of two loci, rhg1 on linkage group $\mathrm{G}$ and Rhg4 on linkage group A2, that confer resistance to the soybean cyst nematode (Heterodera glycines I.). When the polymorphic AFLP band sequence contained a duplicated sequence or could not be converted to a locus-specific STS marker, direct sequencing of BAC clones anchored to a physical map generated locus-specific flanking sequences at the polymorphic locus. When the polymorphism was adjacent to the restriction site used in the AFLP analysis, single primer extension was performed to reconstruct the polymorphism. The six converted AFLP markers represented $996 \mathrm{bp}$ of sequence from alleles of each of two cultivars and identified eight insertions or deletions, two microsatellites and eight single-nucleotide polymorphisms (SNPs). The polymorphic sequences were used to design a non-electrophoretic, fluorometric assay (based on the TaqMan technology) and/or develop electrophoretic STS markers for high-throughput genotype determination during marker-assisted breeding for resistance to cyst nematode. We conclude that the converted AFLP markers contained polymorphism at a 10- to 20-fold higher frequency than expected for adapted soybean cultivars and that the efficiency of AFLP band conversion to STS can be improved using BAC libraries and physical maps. The method provides an efficient tool for SNP and STS discovery suitable for marker-assisted breeding and genomics.
\end{abstract}


Keywords: amplified fragment length polymorphism (AFLP), soybean, positional cloning, disease resistance, soybean cyst nematode

\section{Introduction}

The use of amplified fragment length polymorphism (AFLP) markers for genetic map construction in plants has accelerated genome analysis and genetic improvement. AFLP markers have been used to create genetic maps of both small and large genomes (Alonso-Blanco et al. 1998; Han et al. 1999), including those of many cultivated crop species (Becker et al. 1995; Gerats et al. 1995; Wang et al. 1995; Keim et al. 1997; Maheswaran et al. 1997; Qi et al. 1998). Using AFLP, high-density genetic maps of regions containing economically important genes have been constructed (Meksem et al. 1995, 200la; Ballvora et al. 1995; Thomas et al. 1995). However, AFLP markers do not provide for the high-throughput genotype determination in automated formats that sequence-tagged sites (STSs) allow.

Further advances in quantitative trait (QTL) analysis, positional cloning and molecular breeding will require easy-to-use, sequence-specific markers. The data generated from DNA sequencing of several individuals of a species of plant or animal, using STS libraries or whole genomes, suggests that we can develop DNA markers for every gene in the genome (Schuler 1998; Weissenbach 1998; Lin et al. 1999; Collins et al. 2000), particularly single-nucleotide polymorphism (SNP) markers. SNP markers derived from genome sequencing have been used for saturated map development (Froelich et al. 1999), for candidate gene identification (Cargill et al. 1999) and for high-throughput screening (Germer et al. 2000). However, their discovery in large numbers requires significant investment in DNA sequencing capacity by large laboratories (Germer et al. 2000).

The AFLP technique (Vos et al. 1995) allows small laboratories to rapidly identify thousands of polymorphisms associated with restriction sites. The AFLP bands can be placed on the integrated genetic and physical maps of complex genomes (Klein et al. 2000; Zobrist et al. 2000). The AFL polymorphisms include SNPs, insertions and deletions (indels), and microsatellites (Bradeen and Simon 1998, Wei et al. 1999). Methods for the efficient conversion of AFLP bands to STS markers may allow the high-density STS mapping of whole genomes by small laboratories (Reamon-Buttner and Jung 2000). However, the loss of the original polymorphism during generation of the STS and loss of the locus specificity of the STS (Shan et al. 1999; Wei et al. 1999) pose experimental challenges in generating sequencespecific STSs from AFLP bands.

The soybean cyst nematode (SCN) Heterodera glycines I. causes annual crop losses approaching $\$ 800$ million per annum in the United States. SCN resistance can be simply inherited; two unlinked genes, rhg1 and Rhg4, provide the major portion of resistance in many cultivars (Meksem et al. 1999; Prabhu et al. 1999). SCN resistance can be selected in the greenhouse or by using molecular markers. A high-density genetic map has been constructed for the two loci that underlie resistance to SCN (Meksem et al. 200la). Three AFLP

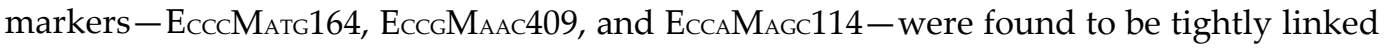
to the Rhg4 locus, and three AFLP markers-EatGMcga87, EcgGMaga116, and EctaMagG113were found to be tightly linked to the rhg1 locus. 
Here we describe the characterization of two alleles of each of these six AFLP markers at the nucleotide sequence level, and the subsequent examination of the nature of AFL polymorphism in soybean. We also demonstrate the construction of high-throughput markers from AFLP band-derived STSs.

\section{Materials and methods}

\section{Plant material}

The mapping population consisted of 96 recombinant inbred lines derived at the F5 generation from a cross of Essex (Smith and Camper 1973) by Forrest (Hartwig and Epps 1973). The recombinant inbred line (RTL) population was advanced to the F5:13 generation from never less than 300 plants per RIL per generation (Hnetkovsky et al. 1996). Forrest is resistant to the soybean cyst nematode (SCN) populations classified as race 3 and Essex is susceptible to all populations of SCN (Chang et al. 1997; Meksem et al. 1999).

\section{DNA isolation}

Soybean genomic DNA used for AFLP analysis was extracted and purified using the Qiagen (Hilden, Germany) Plant Easy DNA Extraction Kit. Primary template DNA was prepared using the restriction enzymes EcoRI and MseI.

\section{AFLP marker analysis}

AFLP analysis was performed as described by Vos et al. (1995), except that the streptavidin bead selection step was omitted. PCRs were performed using primer pairs derived from each of two sets of primers. Primers in the EcoRI set all included the core sequence E (5'GACTGCGTACCAATTC-3') with 1- or 3-bp extensions. Primers of the MseI set have the sequence M (5'-GATGAGTCCTGAGTAA-3') with 1- or 3-bp extensions. The primer combinations $\left(E_{A}\right.$ and $\left.\mathrm{Mc}_{\mathrm{C}}\right)$ and $\left(\mathrm{E}_{\mathrm{C}}\right.$ and $\left.\mathrm{M}_{\mathrm{A}}\right)$ were used for preamplification of the primary template. Three selective nucleotides per primer were used to generate AFLP fragments from the secondary templates. AFLP bands were labeled with ${ }^{33} \mathrm{P}$ by primer phosphorylation, separated by electrophoresis on $4 \%(\mathrm{w} / \mathrm{v})$ PA gels, and visualized by exposing X-ray film to the dried gel (Meksem et al. 2001a).

\section{Cloning and conversion of the AFLP markers}

Target AFLP bands on the autoradiograph were matched to the corresponding area in the gel and the appropriate AFLP fragment was excised from the dried gel. The band was eluted from the gel by incubation in $100 \mu \mathrm{l}$ of water at $4^{\circ} \mathrm{C}$ for $1 \mathrm{~h}$. Sequence isolation in bacterial clones was performed as described by Meksem et al. (1995), except that the pGEM-T vector (Promega, Madison, Wis.) was ligated to PCR-amplified, eluted DNA. DNA sequencing of clones allowed PCR primers to be designed for each unique DNA sequence using Oligo 5.0 software (PE Biosystems, Foster City, Calif.). The PCR product was analyzed on $4 \%(\mathrm{w} / \mathrm{v})$ Metaphor (FMC, Rockland, Me.) agarose gels.

AFLP markers that were dominant or co-dominant, in repulsion and in coupling phases, were used. For dominant AFLP markers, the band representing the dominant allele was cloned and sequenced. The corresponding marker for the recessive allele was isolated by 
PCR using primers designed from the sequence of the dominant band. For apparently codominant AFLP markers, both the coupling- and repulsion-phase bands were cloned simultaneously from the acrylamide gel.

\section{Identification of polymorphisms}

The general strategy employed to identify the specific sequence underlying AFLP band polymorphisms was as follows. If the polymorphism was dominant (e.g., EAtGMcGa87), a primer pair was designed that flanked each of the unique sequences derived from the AFLP band. Each primer pair was used to amplify genomic DNA from both Essex and Forrest. Any primer set that revealed polymorphism (dominant or co-dominant) between the two parents was used to amplify DNA from members of the RIL mapping population. The primer pair that generated a marker on the map corresponding to the map position of the original AFLP band was inferred to be the specific marker STS.

For some AFLP bands the above strategy was ineffective, presumably because the polymorphism lay within or close to the restriction site used for AFLP linker ligation (e.g., EcGGMAGA116). In such cases genomic DNA from the parents and the mapping population was used in a modified AFLP protocol as follows. The pre-amplification step was omitted and the step involving six selective nucleotides was carried out with an extended, highly selective MseI primer to which we added the first $7 \mathrm{nt}$ of the sequenced band, combined with the non-selective EcoRI primer E (e.g., MseI primer M AGAGACT and EcoRI primer E). The MseI primer was end-labeled by phosphorylating the $5^{\prime}$ end with $5 \mu l$ of $\left[\gamma-{ }^{33} \mathrm{P}\right] \mathrm{ATP}$ $\left(3000 \mathrm{Ci} / \mathrm{mmol}\right.$ ) for $30 \mathrm{~min}$ at $37^{\circ} \mathrm{C}$ using $10 \mathrm{U}$ of T4 kinase (Pharmacia, Piscataway, New Jersey). Any primer set that revealed polymorphism (dominant or co-dominant) between the two parents was used to amplify DNA from members of the RIL mapping population. The primer pair that generated a marker on the map corresponding to the map position of the original AFLP band was inferred to be the specific marker STS.

\section{BAC library screening}

The cloned AFLP bands were used to screen the soybean Forrest BAC library by PCR as described by Meksem et al. (2000).

\section{DNA sequencing and BAC sequencing}

Both plasmid and BAC DNA was prepared using the appropriate kit (Qiagen). Sequence determinations were performed by the dideoxy chain-termination method using the Advanced Biosystems (ABT, Foster City, California) Big Dye cycle sequencing method and the ABI 377 automated DNA sequencer.

Plasmids containing inserts derived from AFLP bands were sequenced using M13 universal forward and reverse primers. Direct sequencing of BAC inserts was performed as above with the following modifications: BAC DNA was heated for $30 \mathrm{~min}$ at $70^{\circ} \mathrm{C}$, and sheared by pipetting through a narrow-gauge tip for $2 \mathrm{~min}$. Two primers designed from the target AFLP band sequence were used for sequencing. For the EAtGMcca87-positive BAC insert, the forward primer, named ATG4BACF, was 5'-GGGTTTCAGATAACCGTGGTCG-3'; the reverse primer was the sequence complementary to the ATG4BACF 
primer. The PCR conditions used were $95^{\circ} \mathrm{C}$ for $10 \mathrm{~min}$, then 45 cycles of $95^{\circ} \mathrm{C}$ for $30 \mathrm{~s}$, $55^{\circ} \mathrm{C}$ for $20 \mathrm{~s}$, and $60^{\circ} \mathrm{C}$ for $4 \mathrm{~min}$.

\section{TaqMan analysis}

PCR primers and TaqMan probes were designed with the PE primer express program (PE Biosystems) and were custom synthesized. TaqMan probes were designed for each allele using the EAтGMсса87 insertion/deletion polymorphic sites. The fluorogenic primer sequences were: for the allele named 1, TMA5-RE (5'-TET-TGGTTTCTCTTATGACATTGTT GCC-TAMRA), and for the allele named 2, TMA5-S (5'-6FAM-TTCTCTTATCTTATGACA TTGTTGCC-TAMRA). The forward and reverse primers were the same for both alleles: TMA5-Forward (5'-d-ATCTCTTGGTCTGAGTCTTAT- $3^{\prime}$ ) and TMA5-Reverse (5'-dTATT AACGACCACGGTTATC-3').

The assay uses the $5^{\prime}$ exonuclease activity of Taq polymerase in conjunction with fluorogenic probes for each allele. Amplification was performed in a 384-well thermal cycler (GeneAmp PCR System 9700, PE Biosystems) using a two-step PCR protocol. Incubation at $50^{\circ} \mathrm{C}$ for $2 \mathrm{~min}$ and $95^{\circ} \mathrm{C}$ for $10 \mathrm{~min}$ were followed by 35 cycles of $95^{\circ} \mathrm{C}$ for $15 \mathrm{~s}$ and $60^{\circ} \mathrm{C}$ for $1 \mathrm{~min}$; detection and data analysis were performed as described previously (Meksem et al. 2001b).

\section{Results}

\section{Cloning and sequencing of AFLP bands}

From each AFLP band we sequenced 4-30 clones (mean 15.6) depending on the sequence complexity of the original band. The sequence analysis showed that each AFLP band may be composed of a number of different fragments-of identical size-that differ in sequence. Overall, in our experiments we detected a mean of six sequences per band, with a range of 1-15 sequences per band. In any single AFLP band only one sequence corresponded to the original AFLP marker. The other sequences are bands that share not only the same size 209 (within 1-2 bp) but also the same selective bases at the EcoRI and MseI sites $(100 \%)$. Furthermore, some of the cloned sequences from a given band shared between 6 and $15 \mathrm{bp}$ in common to each side (EcoRI and MseI) of the original AFLP polymorphism (about $30 \%$ of bands).

\section{Identification of polymorphisms}

EATGMcGa87 was a dominant AFLP band in coupling phase with the rhg1 locus. The sequence was used to design primers to screen the Forrest BamHI BAC library by PCR. Under these conditions a single BAC clone was identified. Two internal primers were designed from the EATGMcGA87 resistant allele and DNA from the corresponding BAC was used as template to extend the sequence in both directions from the AFLP marker. Sequencing showed that a single 5-bp indel was responsible for the polymorphic band and no SNPs were present (fig. lb). No additional polymorphisms were detected in about 1,250 bp of flanking sequence. 


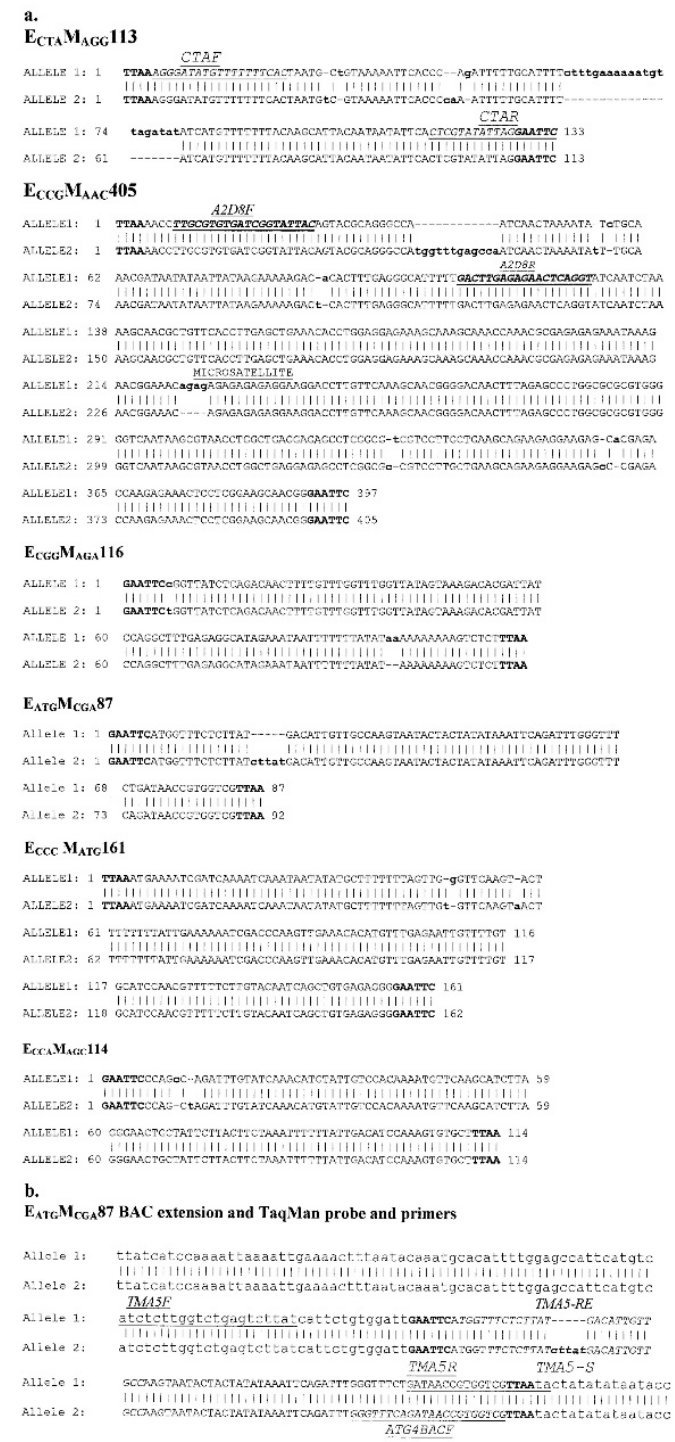

Figure 1a. Genomic sequences of both alleles (resistant Forrest and susceptible Essex) of the converted AFLP markers EatgMcga87, EctaMagg113, EcggMaga116, EccgMaac405, EсcCMATG161, and EccAMAGC114. The italicized and underlined sequences represent the forward and reverse sequence-specific primers used. The sequences in bold capitals represent the original AFLP restriction site. The bold lowercase letters indicate the difference in sequence between the two alleles. 1b. Genomic sequences of the two alleles (resistant and susceptible) of the converted EATGMcGA87 marker. The sequences in italics represent the resistance-specific TaqMan probes TMA5-RE and the susceptible-allele-specific probe TMA5-S. The underlined sequences in uppercase represent the TaqMan forward and reverse primers, the underlined sequence in italics is the ATG4-BACF primer used for sequence extension of the EATGMCGA 87 marker, the BAC-derived extended sequences are indicated in lowercase. 
Sequence comparison of both the resistant and susceptible alleles of the co-dominant AFLP marker EctaMAGg113 revealed polymorphisms including both indels and SNPs. There were four SNPs within $113 \mathrm{bp}$ and one indel (21 bp) (fig. la). Primer sets were designed around the indel site and used to map its genetic position. The genetic position of the identified indel mapped to the same region as the original AFLP.

Sequence comparison of both resistant and susceptible alleles of the dominant AFLP marker EccсMAtG161 revealed SNP polymorphism. There were two SNPs within a stretch of $116 \mathrm{bp}$ (fig. la). Primer sets were designed around the SNP site and used to map its genetic position. The genetic position of the identified indel again mapped to the region of the original AFLP.

Sequence comparison of resistant and susceptible alleles of the dominant AFLP marker EccaMAgc114 uncovered SNP polymorphism adjacent to the EcoRI site. There was one SNP in a 114-bp segment (fig. 1a).

Sequence comparison of resistant and susceptible alleles of the co-dominant AFLP marker ECcGMAAC405 found polymorphisms including both indels and SNPs. There were two indels (12 bp and $4 \mathrm{bp}$ ) and four SNPs within $405 \mathrm{bp}$ (fig. la). The 4-bp indel involved two AG repeats in an $[A G]_{5}$ complex microsatellite sequence. Primer sets were designed around both indel sites and used to map their genetic position. In both cases, the genetic position of the identified indel mapped to the region of the original AFLP.

For the AFLP marker EcGGMAgA116, polymorphisms were found adjacent to both the EcoRI and MseI restriction sites (fig. 1a). For the selective step the six selective nucleotides were replaced by $\mathrm{M}_{A G A} G_{A C T}$ and EC. Using this primer set the polymorphism was detected on sequencing gels and mapping of this sequence to the same location as the original AFLP was successful (fig. 2b). There was one indel (2 bp) and one SNP within 116 bp (fig. 1a). The 2-bp indel was the $[\mathrm{A}]_{2}$ extension of an $[\mathrm{A}]_{8}$ repeat. Primer sets were designed around the indel and SNP sites and used to map their genetic positions. In both cases, the genetic position of the identified polymorphism was identical to the region of the original AFLP.

\section{Examples of the construction of sequence-specific PCR-based markers}

Comparison of the two alleles of the AFLP marker EccGMAAC405 revealed four SNPs, two indels, and one SSR. The insertion of $[\mathrm{AG}]_{2}$ in the $[\mathrm{AG}]_{8}$ repeat of the resistance allele created a microsatellite polymorphism we named SIUC-SAG405. The 4-bp difference between the two alleles at position 224-228 bp was sufficient to allow discrimination between the resistant and susceptible allele after electrophoresis through a $4 \%(\mathrm{v} / \mathrm{w})$ 


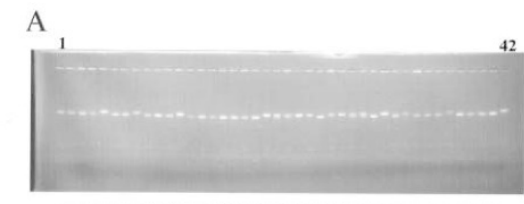

$11112112111211111112 \mathrm{HH} 22122 \mathrm{HH} 12121112111 \mathrm{FE}$

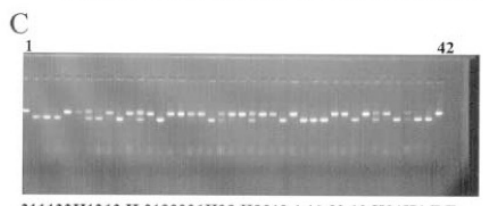

$211122 \mathrm{H} 1212$ H $2122221 \mathrm{H} 22 \mathrm{H} 22121112212$ H21H1 F E
B

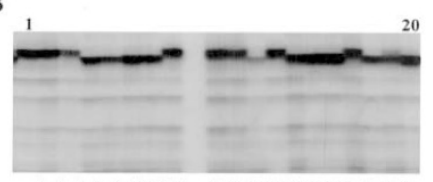

111222 EF 22121112111

D

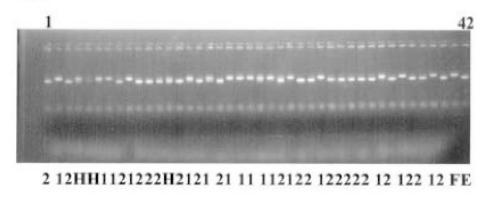

Figure 2. A. PCR amplification product obtained using the EATGMCGA87 sequence-specific primers TMA5 forward and reverse. Lanes 1-40 contain the genomic DNAs from 40 RILs, lanes 41 and 42 contained the parental DNAs. F, Forrest; E, Essex; 1, resistant allele; 2, susceptible allele; $\mathrm{H}$, heterozygous lines. The PCR products were separated by electrophoresis for $1 \mathrm{~h} 30 \mathrm{~min}$ on a $4 \%(\mathrm{w} / \mathrm{v})$ Metaphor gel. B. Partial AFLP profile of the EcGGMAGA116 marker. The six selective nucleotides were replaced by MseI primer MAGAGACT and EcoRI primer E. Lanes 1-6 and 9-20 contained RIL DNA; lane 7, Essex; and lane 8, Forrest. 1, resistant allele; 2, susceptible allele. C. PCR amplification product obtained using the EстAMAgG113 sequence-specific primers CTA forward and reverse. Lanes 1-40 contained DNA from 40 RILs; lanes 41 and 42, the two parental DNAs. F, Forrest; E, Essex; 1 , resistant allele; 2 , susceptible allele; $H$, heterozygous lines. The PCR products were separated as described in 2a. D. PCR amplification product obtained using the EcccMAAC405 sequence-specific primers A2D8 forward and reverse: Lanes 1-40 contain 40 RIL DNA; lanes 41 and 42, the two parental DNAs.

Metaphor agarose gel (not shown). The 12-bp indel at position 42-54 bp was used to design a sequence-specific PCR marker (fig. 2d), and to develop a TaqMan assay for the Rhg4 locus (Meksem et al. 2001b). SNPs were found within the EccGMAAC405. The transversion of the $\mathrm{T}$ at position 327 in the resistant allele to $\mathrm{C}$ at position 337 in the susceptible allele, and of A at position $358 \mathrm{bp}$ in the resistance allele to $\mathrm{C}$ at position $366 \mathrm{bp}$ in the susceptible allele may also be used for high-throughput screening using a SNP-based assay.

An indel of $21 \mathrm{bp}$ was responsible for the polymorphism between Essex and Forrest at the EстAMAgG113 AFLP locus. PCR-based markers were designed to flank the 21-bp indel and shown to be polymorphic, the new marker was named CTA (fig. 2c).

In the EATGMCGA87 marker the insertion of CTTAT to form a tandem repeat in the Forrest allele at position 20-25 bp created a 5-bp polymorphism that was suitable for marker development. PCR primers were designed to develop a sequence-specific PCR assay (fig. 2a), and the new marker was named ATG4. The same indel was used to develop a TaqMan probe named TMA5 to discriminate between the two alleles.

\section{TaqMan analysis}

The EAtGMcGa87-derived ATG4 marker was converted to a fluorogenic probe. Genomic DNA samples from Essex, Forrest, and 96 RILs were analyzed using the Taqman PCR pro- 
tocol. Four distinct classes were detected based on the raw fluorescence signals of the reporter dyes FAM and TET from the "Dye Component" field of the sequence detection software (fig. 3). The FAM:TET ratio of the four classes differed by the cutoff used to separate the heterogeneous (heterozygote-derived) class of RILs. The fluorescence ratios were as follows: no amplification, FAM and TET both less than 6 units; allele 1 homozygous, FAM $<7$, TET > 7; allele 2 homozygous, FAM $>10$, TET $<5$; and heterogeneous for allele 1 and allele 2 , FAM $>7$, TET $=5-8$.

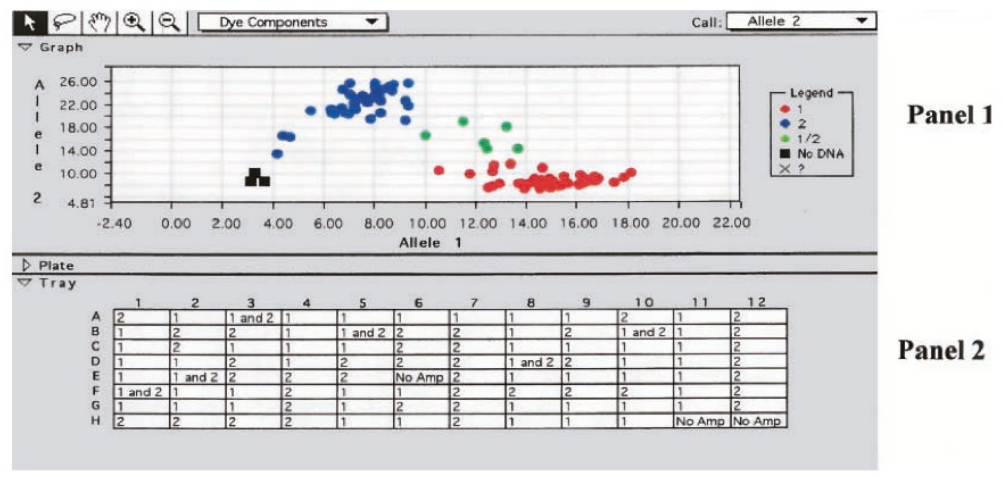

Figure 3. Detection of the TMA5 (EatgMcga87) marker polymorphism by the Taqman method allows allelic discrimination of soybean genotypes with manual selection of genotypes. Data for 90 individuals from an F5-derived population of RILs from the cross Essex $\times$ Forrest that segregate for resistance to $\mathrm{SCN}$ are shown. Upper panel The fluorescent signals were viewed under the "Dye Component" field of the sequence detection software, and the TMA5 genotypes were manually selected based on the ratio of FAM to TET signals. Allele 1, homozygous Forrest type: TET/FAM greater than 2. Allele 2, homozygous Essex type: FAM/TET greater than 2. If the TET level was less than two-fold greater or lesser than the FAM level, the individual was scored as heterozygous Essex/Forrest (1/2). Lower panel The Excel spreadsheet shows the scores for the samples as they were arranged in the 96-well plate. There was no DNA in wells H11 and H12. Essex DNA was placed in well Al, Forrest DNA in well Bl, and the RTL DNA was arrayed in the rest of the 96-well plate (C1 to G12). 1, resistant allele; 2, susceptible allele; 1 and 2, heterozygous lines.

PCR followed by electrophoretic genotype determination on $4 \%(\mathrm{w} / \mathrm{v})$ agarose Metaphor gels with TMA5F and TMA5R primers was used to validate the TaqMan data (fig. $2 a)$. There was complete agreement $(100 \%)$ between the two methods for discriminating between allele 1 and 2 . However, the TaqMan assay identified six lines that were heterogeneous for resistance to SCN, whereas the PCR-based gel method failed to detect two of them. The phenotype of the RILs and the genotype of linked markers suggested that the TaqMan method was more accurate for identifying members of the heterogeneous class. 


\section{Discussion}

The 30\% of AFLP band-derived sequences that shared 6-15 bp of sequence from each side (EcoRI and MseI) with the original AFLP marker was unexpected. These sequences may derive from the repetitive sequences and homoeologous loci that characterize the soybean genome (Shoemaker et al. 1996). They were detected with all primer combinations except one, which suggests that they are not derived from a single mobile genetic element that carries EcoRI and/or MseI sites. They may reflect convergent evolution of the context of EcoRI and MseI sites, the latter are relatively GC rich compared to the bulk soybean genome. Whatever the mechanism, the phenomenon of context conservation could explain the higher frequency of AFLP polymorphism compared to RFLP polymorphism in soybean (Keim et al. 1997).

Historically, the conversion of AFLPs to sequence-tagged DNA markers for fine-scale mapping by primer extension has been difficult (Meksem et al. 1995). Progress has been made in distinguishing the "true" sequence that corresponds to the original AFLP marker by improved vector ligation (Reamon-Büttner and Jung 2000). However, reconstruction of the original polymorphism remains difficult (Shan et al. 1999) since the cloning procedure required for the AFLP conversion often contributes to the loss of the original polymorphism (Wei et al. 1999). Bradeen and Simon (1998) used inverse PCR as a procedure to convert dominant AFLP to co-dominant STS markers. However, the preparation of the template DNA and optimization of PCR conditions for each primer-target combination limit throughput for inverse or anchored PCR in complex duplicated genomes (Ochman et al. 1993). The use of marker-anchored BAC libraries allows AFLP polymorphism to be correctly positioned (Klein et al. 2000; Meksem et al. 2000; Zobrist et al. 2000), suggesting that AFLP-derived STS markers can be used to verify or fill gaps in physical maps. We showed that direct BAC sequencing could generate flanking sequences during conversion of the EAtGMcGa87 AFLP marker. When direct conversion of the AFLP to an STS marker is not feasible due to small band size or because the band is heterogeneous, the BAC clone can be used to generate a secondary sequence-tagged site. In addition, physically linked microsatellites can be generated from AFLP-anchored BAC DNA to allow rapid conversion to markers with higher allelic diversity (Cai et al. 1995; Meksem et al. 1998, 2000; Cregan et al. 1999).

Sequencing of plant and animal genomes has changed linkage analysis by DNA markers (Cho et al. 1999; Germer et al. 2000). However, few allelic variants in crop species will be sequenced to high redundancy in the near future. Unless new DNA sequencing technologies that combine reliability and cost effectiveness are invented, AFLP will continue to be used for rapid and efficient genome-wide allele scoring and linkage mapping (Innan et al. 1999). AFLP-based genetic maps for most cultivated crop species are sufficient to provide the genetic framework for developing MAS programs (Meksem et al. 2001b). AFLP-derived STSs can be used to create isogenic lines for fine-structure mapping of QTLs or to introgress genes into adapted cultivars (Tanksley and Nelson 1996; Tanksley et al. 1996). Reliable, co-dominant and cost-effective markers are necessary for high-throughput genotyping tasks (Bradeen and Simon 1998). 
The conversion of AFLP markers to single-locus STS markers physically linked to regions encompassing the two loci underlying resistance to $\mathrm{SCN}$ in cv. Forrest allowed finescale mapping in both a large RIL population and a large population of near-isogenic lines (Meksem et al. 2000). The same markers were introduced in our marker-assisted selection program for generating new cultivar varieties with stable resistance to SCN (Meksem et al. $2001 \mathrm{~b}$; this work). The TaqMan assay described here was highly sensitive in detecting heterozygeneous lines and discriminating between the two alleles (Kalinina et al. 1997; Meksem et al. 200lb). Its application in the SIUC breeding program has reduced exposure to the hazardous ethidium bromide and decreased the frequency of scoring errors (Livak et al. 1995).

Acknowledgments - Particular thanks to Dr. M. E. Schmidt and J. H. Klein III for excellent management of the field program in Southern Illinois. Thanks to Rubina Ahsan for sequencing, and to all the workers on the field team at Southern Illinois University at Carbondale from 1980 to 1999. This work was supported in part by grants from the Illinois Soybean Program Operating Board Nos. 9420-143-3 and 97-19-132-3, United Soybean Board Nos. 96-20-431 and 98-20-432, and NSF Project DBI9872635. This work has been carried out in compliance with the current laws governing genetic experimentation in the USA and the state of Illinois.

\section{References}

Alonso-Blanco C, Peeters AJ, Koornneef M, Lister C, Dean C, van den Bosch N, Pot J, Kuiper MT (1998) Development of an AFLP based linkage map of Ler, Col and Cvi Arabidopsis thaliana ecotypes and construction of a Ler/Cvi recombinant inbred line population. Plant J 2:259-271.

Ballvora A, Hesselbach J, Niewohner J, Leister D, Salamini F, Gebhardt C (1995) Marker enrichment and high-resolution map of the segment of potato chromosome VII harbouring the nematode resistance gene Grol. Mol Gen Genet 249:82-90.

Becker J, Vos P, Kuiper M, Salamini F, Heun M (1995) Combined mapping of AFLP and RFLP markers in barley. Mol Gen Genet 249:65-73.

Bradeen JM, Simon PW (1998) Conversion of an AFLP fragment linked to the carrot Y2 locus to a simple codominant PCR-based marker form. Theor Appl Genet 97:960-967.

Cai L, Taylor JF, Wing RA, Gallagher DS, Woo S-S, Davis SK (1995) Construction and characterization of a bovine bacterial artificial chromosome library. Genomics 29:413-425.

Cargill M, Altshuler D, Ireland J, Sklar P, Ardlie K, Patil N, Shaw N, Lane CR, Lim EP, Kalyanaraman N, Nemesh J, Ziaugra L, Friedland L, Rolfe A, Warrington J, Lipshutz R, Daley GQ, Lander ES (1999) Characterization of single-nucleotide polymorphisms in coding regions of human genes. Nature Genet 22:231-238.

Chang SJC, Doubler TW, Kilo V, Suttner R, Klein J, Schmidt ME, Gibson PT, Lightfoot DA (1996) Two additional loci underlying durable field resistance to soybean sudden death syndrome (SDS). Crop Sci 36:1684-1688.

Chang SJC, Doubler TW, Kilo V, Suttner R, Klein J, Schmidt ME, Gibson PT, Lightfoot DA (1997) Association of field resistance to soybean sudden death syndrome (SDS) and cyst nematode (SCN). Crop Sci 37:965-971.

Cho RJ, et al (1999) Genome-wide mapping with biallelic markers in Arabidopsis thaliana. Nature Genet 23:203-207. 
Collins A (2000) Mapping in the sequencing era. Hum Hered 50:76-84.

Cregan PB, Mudge J, Fickus EW, Denny R, Danesh R, Young ND (1999) Targeted isolation of simple sequence repeat markers through the use of bacterial artificial chromosomes. Theor Appl Genet 99:918-928.

Froelich S, Boulden H, Rizzu P, Chakraverty S, Baker M, Kwon J, Nowotny P, Isaacs A, Nowotny V, Wauters E, van Baren MJ, Oostra BA, Hardy J, Lannfelt L, Goate A, Hutton M, Lendon CL, Heutink P (1999) Construction of a detailed physical and transcript map of the FTDP-17 candidate region on chromosome 17q21. Genomics 60:129-136.

Gerats T, De Keukeleire P, Deblaere R, Van Montagu M, Zethof J (1995) Amplified fragment length polymorphism (AFLP) mapping in Petunia: a fast and reliable method for obtaining a genetic map. Acta Hort 420:58-61.

Germer S, Holland MJ, Higuchi R (2000) High-throughput SNP allele-frequency determination in pooled DNA samples by kinetic PCR. Genome Res 10:258-266.

Han HJ, vanEck, DeJeu MJ, Jacobsen E (1999) Optimization of AFLP fingerprinting of organisms with a large-sized genome: a study on Alstroemeria spp. Theor Appl Genet 98:465-471.

Hartwig EE, Epps JM (1973) Registration of Forrest soybeans. Crop Sci 13:287.

Hnetkovsky N, Chang SJC, Doubler TW, Gibson PT, Lightfoot DA (1996) Genetic mapping of loci underlying field resistance to soybean sudden death syndrome (SDS). Crop Sci 36:392-400.

Innan H, Terauchi R, Kahl G, Tajima F (1999) A method for estimating nucleotide diversity from AFLP data. Genetics 151:1157-1164.

Kalinina O, Lebedeva I, Brown J, Silver J (1997) Nanolitre scale PCR with TaqMan detection. Nucleic Acids Res 25:1999-2004.

Keim P, Schupp JM, Travis SE, Clayton K, Zhu T, Shi L, Ferreira A, Webb DM (1997) A high-density genetic map of soybean based upon AFLP markers. Crop Sci 37:537-543.

Klein PE, Klein RR, Cartinhour SW, Ulanch PE, Dong J, Obert JA, Morishige DT, Schlueter SD, Childs KL, Ale M, Mullet JE (2000) A high-throughput AFLP-based method for constructing integrated genetic and physical maps: progress toward a sorghum genome map. Genome Res 10:789-807.

Lin X, et al (1999) Sequence and analysis of chromosome 2 of the plant Arabidopsis thaliana. Nature 402:761-768.

Livak K, Flood SJA, Marmo J, Guisti J, Deez K (1995) Oligonucleotides with fluorescent dyes at opposite ends provide a quenched probe system useful for detecting PCR product and nucleic acid hybridization. PCR Methods Appl 4:357-362.

Maheswaran M, Subudhi PK, Nandi S, Xu JC, Parco A, Yang DC, Huang N (1997) Polymorphism, distribution, and segregation of AFLP markers in a doubled haploid rice population. Theor Appl Genet 94:39-45.

Meksem K, Leister D, Peleman J, Zabeau M, Salamini F, Gebhardt C (1995) A high-resolution map of the vicinity of the RI locus on chromosome $\mathrm{V}$ of potato based on RFLP and AFLP markers. Mol Gen Genet 249:74-81.

Meksem K, Zhang H-B, Lightfoot DA (1998) A plant transformation-ready bacterial artificial chromosome library for soybean: applications in chromosome walking and genome-wide physical mapping. Soybean Genet Newslett 25:139-141.

Meksem K, Doubler TW, Chancharoenchai K, Njiti V, Chang SJC, Rao Arelli AP, Cregan PE, Gray LE, Gibson PT, Lightfoot DA (1999) Clustering among loci underlying soybean resistance to Fusarium solani, SDS and SCN in near-isogenic lines. Theor Appl Genet 99:1131-1142. 
Meksem K, Ruben E, Zobrist K, Zhang H-B, Lightfoot DA (2000) Two large insert libraries for soybean: applications in cyst nematode resistance and genome wide physical mapping. Theor Appl Genet 101:747-755.

Meksem K, Pantazapoulos P, Njiti VN, Hyten LD, Arelli PR, Lightfoot DA (2001a) “Forrest" resistance to soybean cyst nematode is bigenic: saturation mapping of the Rhg1 and Rhg4 loci. Theor Appl Genet 102 (in press).

Meksem K, Ruben E, Hyten D, Schmidt ME, Lightfoot DA (2001 b) High-throughput genotyping for a polymorphism linked to soybean cyst nematode resistance gene Rhg4 using Taqman probes. Mol Breeding, in press.

Ochman H, Ayala FJ, Hartl DL (1993) Use of polymerase chain reaction to amplify segments outside boundaries of known sequences. Methods Enzymol 218:309-321.

Prabhu RR, Njiti VN, Bell-Johnson B, Johnson JE, Schmidt ME, Klein JH, Lightfoot DA (1999) Selecting soybean cultivars for dual resistance to soybean cyst nematode and sudden death syndrome using two DNA markers. Crop Sci 39:982-987.

Qi X, Stam P, Lindhout P (1998) Use of locus-specific AFLP markers to construct a high-density molecular map in barley. Theor Appl Genet 96:376-384.

Reamon-Buttner SM, Jung C (2000) AFLP-derived STS markers for the identification of sex in Asparagus officinalis L. Theor Appl Genet 100:432-438.

Schuler GD (1998) Electronic PCR: bridging the gap between genome mapping and genome sequencing. Trends Biotechnol 16:456-459.

Shan X, Blake TK, Talbert LE (1999) Conversion of AFLP markers to sequence-specific PCR markers in barley and wheat. Theor Appl Genet 98:1072-1078.

Shoemaker RC, Polzin K, Labate J, Specht J, Brummer EC, Olson T, Young N, Concibido V, Wilcox J, Tamulonis JP, Kochert G, Boerma HR (1996) Genome duplication in soybean (Glycine subgenus Soja). Genetics 144:329-338.

Smith TJ, Camper HM (1973) Registration of Essex soybeans. Crop Sci 13:495.

Tanksley SD, Nelson JC (1996) Advanced backcross QTL analysis: a method for the simultaneous discovery and transfer of valuable QTLs from unadapted germplasm into elite breeding lines. Theor Appl Genet 92:191-203.

Tanksley SD, Grandillo S, Fulton TM, Zamir D, Eshed T, Petiard V, Lopez J, Beck-Bunn J (1996) Advanced backcross QTL analysis in a cross between an elite processing line of tomato and its wild relative L. pimpinellifolium. Theor Appl Genet 92:213-224.

Thomas CM, Vos P, Zabeau M, Jones DA, Norcott KA, Chadwick BP, Jones JD (1995) Identification of amplified restriction fragment polymorphism (AFLP) markers tightly linked to the tomato $C f$ 9 gene for resistance to Cladosporiumfulvum. Plant J 5:785-794.

Vos P, Hogers R, Bleeker M, Reijans M, van de Lee T, Hornes M, Frijters A, Pot J, Peleman J, Kuiper M (1995) AFLP: a new technique for DNA fingerprinting. Nucleic Acids Res 23:4407-4414.

Wang YH, Thomas CE, Dean RA (1997) A genetic map of melon (Cucumis melo L.) based on amplified fragment length polymorphism (AFLP) markers. Theor Appl Genet 96:791-798.

Wei F, Gobelman-Werner K, Morroll SM, Kurth J, Mao L, Wing R, Leister D, Schulze-Lefert P, Wise RP (1999) The Mia (powdery mildew) resistance cluster is associated with three NBS-LRR gene families and suppressed recombination within a 240-kb DNA interval on chromosome SS (1HS) of barley. Genetics 153: 1929-1948.

Weissenbach J (1998) The Human Genome Project: from mapping to sequencing. Clin Chem Lab Med 36:511-514. 
K. Meksem et Al., Molecular Genetics and Genomics 265 (2001)

Zobrist K, Meksem K, Wu C, Tao Q, Zhang H, Lightfoot DA (2000) Integrated physical mapping of the soybean genome: a tool for rapid identification of economically important genes. Soybean Genet Newslett 27:10-15. 